\title{
Effect of time and body position on ventilation in premature infants
}

\author{
Judith Hough ${ }^{1,2}$, Anthony Trojman ${ }^{1}$ and Andreas Schibler ${ }^{2}$
}

BACKGROUND: Infants with respiratory dysfunction undergo regular position changes to improve lung function however it is not known how often a position change should occur. This study measured changes in lung function occurring over time after repositioning in preterm infants.

METHODS: Changes in end-expiratory level (EEL) and ventilation distribution were measured $30 \mathrm{mins}, 2 \mathrm{~h}$, and $4 \mathrm{~h}$ after repositioning into either prone, quarter turn from prone, or supine using Electrical Impedance Tomography (EIT). Physiological measurements were also taken.

RESULTS: Sixty preterm infants were included in the study. Infants receiving respiratory support (mechanical ventilation or continuous positive airway pressure (CPAP)) had improved ventilation homogeneity after $2 \mathrm{~h}(P<0.01)$, maintained at $4 \mathrm{~h}$. Spontaneously breathing infants had improved homogeneity at $2 \mathrm{~h}(P<0.01)$ and improved global EEL after $4 \mathrm{~h}(P<0.01)$ whereas infants receiving CPAP demonstrated an improved global EEL at $2 \mathrm{~h}(P<0.01)$.

CONCLUSION: Regional ventilation distribution is influenced by time independent of changes due to body position. Differences exist between infants on ventilatory support compared with those who are spontaneously breathing. Infants receiving ventilatory support have a physiological peak in lung function after $2 \mathrm{~h}$ which remains above baseline at $4 \mathrm{~h}$. A change in body position facilitates an improvement in lung function in infants on ventilatory support.

T he highest risk factor for mortality or morbidity in premature infants next to the immature brain is a reduced lung function due to immaturity of the lung (1). Infants born at $32 \mathrm{wk}$ gestational age or less have underdeveloped lungs with impaired gas exchange (2). Most of these premature infants are at high risk of respiratory failure (3) and their primary care involves the promotion of respiratory function. With the introduction of surfactant and continuous positive airway pressure (CPAP), significant reduction in mechanical ventilation and its associated risk for lung disease has been achieved over the last two decades. Babies with respiratory dysfunction undergo regular position changes, a practice used to improve gas exchange, optimize respiratory function, maintain skin integrity (4), and promote neuromotor function (5).

Repositioning can enhance lung function by improving respiratory rate (RR)(6), oxygenation (7), and respiratory muscle strength (8). Additionally, modifying positions in preterm infants instantaneously alters regional ventilation distribution (9). However, the changing of positions and handling during cares are also causes of physiological stress $(10,11)$. As a result infants are minimally handled and cue-based care is adopted in many neonatal intensive care units, (12) which means that if the infant displays no signs of behavioral or physiological distress then it is recommended handling should be avoided. These caregiving practices have been introduced solely to reduce physiological and behavioral distress in preterm infants but is it coming at a cost to lung function?

Regularly alternating nursing positions is necessary as each position has different benefits (5). However it has not been established how long a position change is effective and potentially infants may require repositioning more often than what is currently being practiced to receive the benefits in lung function.

We have previously published on the differences between positions measured after $30 \mathrm{~min}$ in this group of preterm infants $(13,14)$, findings which have subsequently been supported by Lupton-Smith et al. (15). In these previous studies we allowed a washout of the effect of body position over $4 \mathrm{~h}$ but only reported on the effect of position change after $30 \mathrm{~min}$. During our analysis we discovered what appeared to be an effect of time. As a result, this study is reporting the effect of time with the aim of this study being to determine the changes in ventilation distribution and gas exchange occurring over time after repositioning in preterm infants.

\section{RESULTS}

Patient Characteristics

The study comprised 60 premature infants, 33 males and 27 females (Table 1). Forty-eight infants were dependent on respiratory support (24 on mechanical ventilation; 24 on $\mathrm{CPAP}$ ). Twelve infants were spontaneously breathing and were significantly older and heavier $(P<0.01)$ than the infants on respiratory support. Although body weight affects amplitude,

${ }^{1}$ School of Physiotherapy, Australian Catholic University, Banyo, Australia; ${ }^{2}$ Mater Research Institute - The University of Queensland, South Brisbane, Australia. Correspondence: Judith Hough (judith.hough@acu.edu.au)

Received 23 March 2016; accepted 5 April 2016; advance online publication 22 June 2016. doi:10.1038/pr.2016.116 
Articles | Houghetal.

Table 1. Demographic data of the infants-mean (SD)

\begin{tabular}{|c|c|c|c|c|}
\hline & Spontaneously breathing $(n=12)$ & Mechanically ventilated $(n=24)$ & $\operatorname{CPAP}(n=24)$ & $P$-value \\
\hline Gestational age (wk) & $32.0(0.0)$ & $27.4(1.9)$ & $28.7(1.8)$ & $<0.01^{*}$ \\
\hline Postnatal age (wk) & $1.8(1.2)$ & $1.7(0.9)$ & $4.7(3.8)$ & $<0.05^{*}$ \\
\hline Current weight (g) & $1,805(264)$ & $1,081(279)$ & $1,085(264)$ & $<0.01^{*}$ \\
\hline Male:Female ${ }^{a}$ & $2: 10$ & $15: 9$ & $16: 8$ & $0.01 *$ \\
\hline
\end{tabular}

${ }^{*} P<0.05$; CPAP, continuous positive airway pressure; SD, standard deviation. ${ }^{a}$ Number of each gender.

Note: This data has been previously reported $(13,14)$.

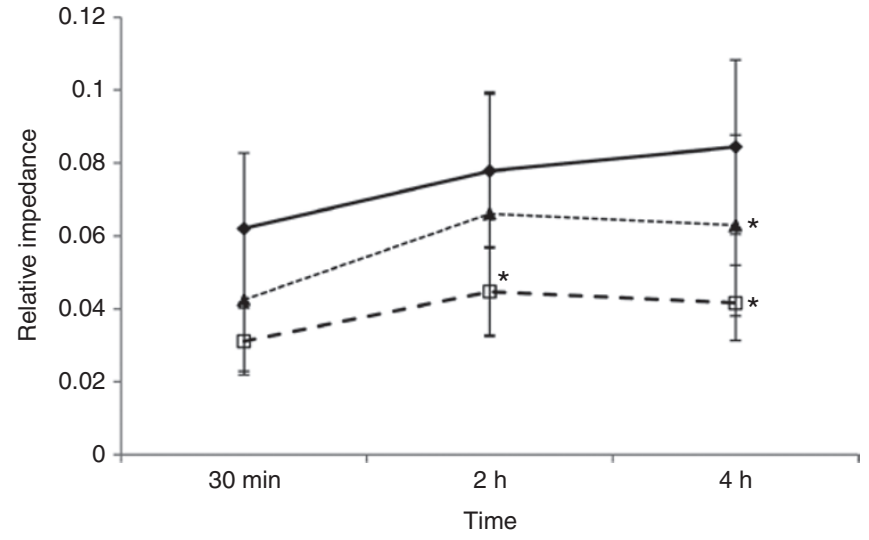

Figure 1. The change in posterior regional impedance amplitude in infants that were spontaneously breathing or receiving positive pressure ventilatory support at 30 mins, $2 \mathrm{~h}$, and $4 \mathrm{~h}$ after repositioning. Means and confidence intervals displayed. Ventilated infants had significantly $(*)$ increased relative impedance amplitude at $4 \mathrm{~h}(P=0.02)$ compared with 30 mins; infants on continuous positive airway pressure (CPAP) had significantly increased amplitude at both $2 \mathrm{~h}(P=0.02)$ and $4 \mathrm{~h}(P=0.03)$; spontaneously breathing infants had no significant changes. Line with triangles $=$ ventilated infants; line with squares $=$ infants on CPAP; line with diamonds $=$ spontaneously breathing infants.

there is no direct comparison between groups. No interactions were found between time and position for all the measured parameters; results are reported for time only.

\section{Changes in Regional Impedance Amplitudes}

In the mechanically ventilated infants, regional impedance amplitudes increased in the posterior lung regions over the 4-h period, reaching significance at $4 \mathrm{~h}(P=0.02)$ (Figure 1). A similar pattern occurred in the infants on CPAP with an increased regional impedance amplitude of the posterior lung at $2 \mathrm{~h}(P=0.02)$ and at $4 \mathrm{~h}(P=0.03)$ compared with the 30 -min measure. The amplitude in the right lung was also significantly increased at $2 \mathrm{~h}(P<0.01)$ but not at $4 \mathrm{~h}(P=0.94)$ in the infants on CPAP. No significant changes in impedance amplitudes occurred over time in any of the other regions of interest (ROIs) or in the spontaneously breathing infants.

\section{Changes in End Expiratory Level}

In the mechanically ventilated infants there were no significant changes in end expiratory level (EEL) over time (Table 2). For the infants on CPAP, the global and all regional EEL's significantly increased (Figure 2$)$ at $2 \mathrm{~h}(P<0.01)$ but returned to the 30-min baseline level at $4 \mathrm{~h}(P=0.58)$. In the spontaneously breathing infants, there was a gradual increase in the global EEL over time reaching significance at $4 \mathrm{~h}(P<0.01)$.

\section{Changes in Ventilation Homogeneity}

In both the mechanically ventilated infants and infants on CPAP, the global inhomogeneity (GI) index was significantly decreased at both 2 and $4 \mathrm{~h}(P<0.01)$ (Figure 3$)$ indicating more homogenous ventilation over time. The spontaneously breathing infants also demonstrated a reduced GI index at $2 \mathrm{~h}$ $(P<0.01)$ which has returned to baseline by $4 \mathrm{~h}(P=0.84)$.

\section{Changes in Physiological Parameters}

There were no significant changes in RR, fraction of inspired oxygen or oxygen saturations over the study period for any of the study infants. There was a significantly increased heart rate in the infants on CPAP after $2 \mathrm{~h}(P<0.01)$, from $142.6 \mathrm{bpm}$ to $145.7 \mathrm{bpm}$, however this change was not clinically relevant.

\section{DISCUSSION}

In premature infants receiving ventilatory support for respiratory distress syndrome, there were multiple significant changes in ventilation distribution occurring over the 4 -h period after each position change.

- Regional impedance amplitudes in the posterior lung region in both the mechanically ventilated and the infants on CPAP were significantly improved at $4 \mathrm{~h}$ after a position change whereas in the spontaneously breathing infants, there was no change in amplitude. It is important to note that regional impedance changes are a surrogate marker for regional volume changes.

- Infants receiving CPAP demonstrated an increased EEL at $2 \mathrm{~h}$ that was not maintained at $4 \mathrm{~h}$ whereas in the mechanically ventilated infants there were no significant changes in EEL over time, probably as a result of a large variability in EEL. Infants who were spontaneously breathing demonstrated a steady increase in EEL which reached significance at $4 \mathrm{~h}$.

- All three groups demonstrated a significantly improved homogeneity of ventilation after $2 \mathrm{~h}$. However, while the infants receiving positive pressure ventilatory support continued to have improved ventilation homogeneity at $4 \mathrm{~h}$, the spontaneously breathing infants had little difference in the GI index at $4 \mathrm{~h}$ when compared with the 30 -min measure. 
Table 2. Change in end expiratory level (EEL) in preterm infants over time for each ventilatory mode EEL

\begin{tabular}{|c|c|c|c|c|}
\hline Controls & $30 \mathrm{~min}$ & $2 \mathrm{~h}$ & $4 \mathrm{~h}$ & $P$-value \\
\hline Global & $0.21(0.07-0.36)$ & $0.32(0.14-0.48)$ & $0.36(0.19-0.53)$ & $0.02^{*}$ \\
\hline ROI_right & $0.21(0.03-0.39)$ & $0.38(0.08-0.68)$ & $0.39(0.15-0.63)$ & $0.01^{*}$ \\
\hline ROI_anterior & $0.11(-0.08-0.31)$ & $0.22(0.01-0.46)$ & $0.21(0.01-0.41)$ & 0.44 \\
\hline ROI_posterior & $0.28(0.14-0.42)$ & $0.36(0.23-0.51)$ & $0.43(0.28-0.59)$ & $0.04^{*}$ \\
\hline \multicolumn{5}{|l|}{ CPAP } \\
\hline ROI_right & $0.16(-0.09-0.42)$ & $0.42(0.23-0.61)$ & $0.27(-0.04-0.58)$ & $<0.01^{*}$ \\
\hline ROI_left & $0.16(-0.06-0.40)$ & $0.42(0.06-0.64)$ & $0.27(-0.16-0.58)$ & $<0.01 *$ \\
\hline ROI_anterior & $0.11(-0.09-0.31)$ & $0.38(0.13-0.63)$ & $0.23(-0.04-0.50)$ & $<0.01^{*}$ \\
\hline ROI_posterior & $0.21(-0.4-4.56)$ & $0.37(0.13-0.62)$ & $0.23(-0.11-0.58)$ & $<0.01^{*}$ \\
\hline ROI_Left & $0.41(-0.71-1.54)$ & $1.06(-0.63-2.76)$ & $1.22(-0.62-3.06)$ & 0.18 \\
\hline ROI_Anterior & $0.38(-0.62-1.38)$ & $0.90(-0.65-2.46)$ & $0.38(-0.50-2.89)$ & 0.06 \\
\hline ROI_Posterior & $0.39(-0.28-1.06)$ & $0.81(-0.09-1.71)$ & $0.81(-0.21-1.83)$ & 0.83 \\
\hline
\end{tabular}

Mean and confidence intervals displayed.

${ }^{*} P<0.05$.

CPAP, continuous positive airway pressure; $\mathrm{ROI}$, region of interest.

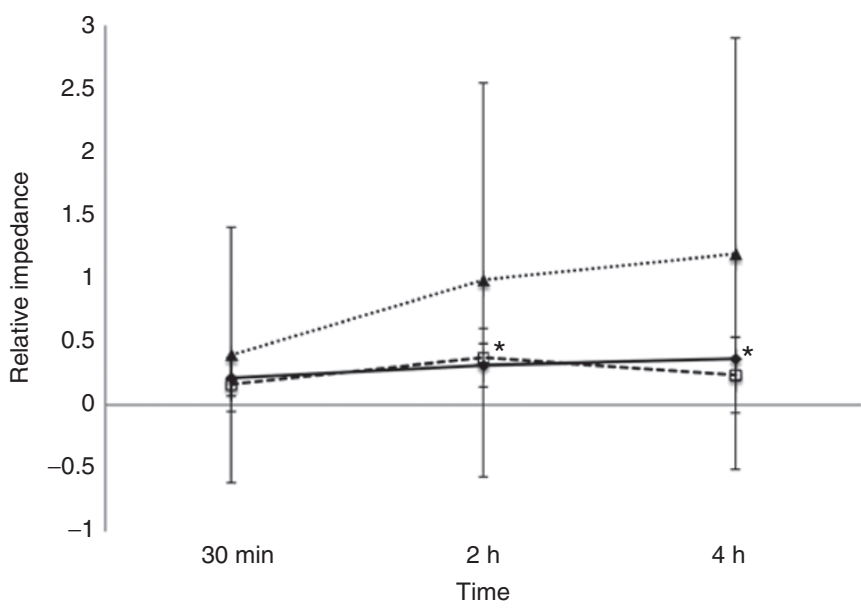

Figure 2. The change in global end-expiratory level in preterm infants that were spontaneously breathing or receiving positive pressure ventilatory support at 30 mins, $2 \mathrm{~h}$, and $4 \mathrm{~h}$ after repositioning. Means and confidence intervals displayed. Compared with 30 mins, there was a significantly $(*)$ increased end expiratory level $(\mathrm{EEL})$ at $2 \mathrm{~h}(P<0.01)$ in the infants receiving continuous positive airway pressure (CPAP) and at $4 \mathrm{~h}(P<0.01)$ in spontaneously breathing infants. Line with triangles $=$ ventilated infants; line with squares $=$ infants on CPAP; line with diamonds $=$ spontaneously breathing infants.

The most challenging outcome of this study is to interpret the finding that after a position change in a random order, no significant impact of the position on regional ventilation distribution has occurred. In the past, gravity has been considered the predominant influence on ventilation distribution in neonates $(16,17)$. However, recent studies have shown that ventilation distribution of the neonate is less dependent on

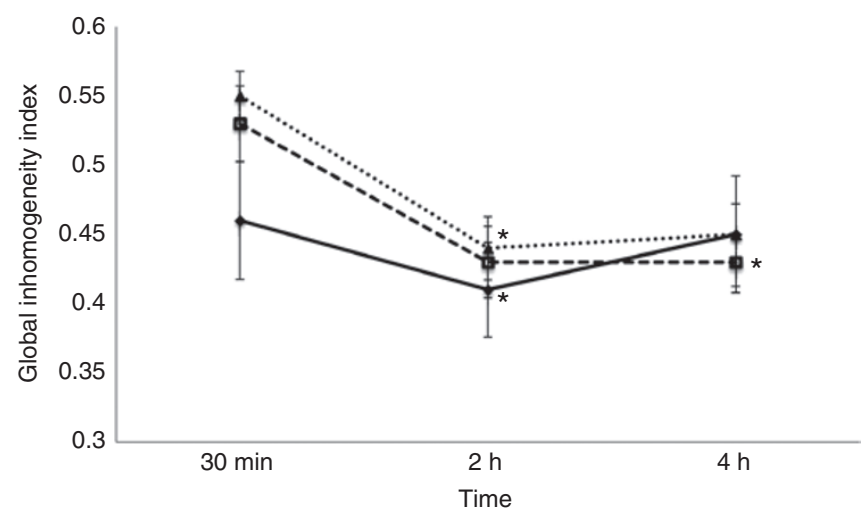

Figure 3. The change in the global inhomogeneity (GI) index in infants that were spontaneously breathing or receiving positive pressure ventilatory support at $30 \mathrm{mins}, 2 \mathrm{~h}$ and $4 \mathrm{~h}$ after repositioning. Means and confidence intervals displayed. Infants receiving respiratory support had significantly $\left.{ }^{*}\right)$ reduced $\mathrm{Gl}$ at $2 \mathrm{~h}$ and $4 \mathrm{~h}$ compared with 30 mins $(P<$ 0.01 ), whereas infants that were spontaneously breathing demonstrated significantly reduced $\mathrm{Gl}$ at $2 \mathrm{~h}$ only $(P<0.01)$. Line with triangles $=$ ventilated infants; line with squares $=$ infants on CPAP; line with diamonds = spontaneously breathing infants.

gravity, but more dependent on some complex anatomical factors $(13-15,18,19)$. The underlying anatomical structure of the lung is now considered one of the most important factors in causing heterogeneity in pulmonary perfusion and ventilation in both healthy and diseased lungs (20).

Our study expands on the findings reported in this group of infants in our previous papers $(13,14)$ and shows that the effect of time is independent of changes in ventilation distribution due to body position. Our results show that the fact of a 
"change" in body position leads to a change in lung function and not just the position on its own.

Immediately after a position change there was an increased GI which significantly decreased over the next $2-4 \mathrm{~h}$. This effect was most dominant in infants receiving respiratory support. A possible explanation is that with the position change a time dependent fluid/interstitial change occurred over time. Such an effect has been described in ventilated adults scanned with a computerized tomography scan after a change in position (21). In this context it is important that the electrical impedance tomography (EIT) measurements are understood as functional imaging and not anatomical.

While this improved ventilation homogeneity may have occurred as a result of repositioning, infants receiving respiratory support also had suction performed prior to their position change and it has been recently reported that suctioning, while it does not disturb the global lung volume, may still cause regional atelectasis and as a result affect ventilation homogeneity (22). Even though ventilation homogeneity was affected after handling, our results demonstrated that after $2 \mathrm{~h}$ there were minimal changes in GI in all three study groups. The changes occurring in the spontaneously breathing infants were less apparent, most likely because healthy lungs have a more homogenous distribution of air when compared with diseased lungs with low positive end-expiratory pressure (PEEP) $(23,24)$.

Accompanying the decreased ventilation inhomogeneity was an increase in regional ventilation of the posterior lung in the infants on ventilatory support. This change was significant only in the posterior lung despite the different positions. Previous studies have also shown ventilation distribution favoring the posterior (dorsal) lung regions $(13,14,18,25)$. It has been reported that the utilization of PEEP redistributes ventilation toward the dependent areas of the lungs (26) although PEEP redistributes pulmonary perfusion to dependent lung regions in patients who are supine but not in prone (27). The normal distribution of ventilation and blood flow change under pathological conditions and during mechanical ventilation due to changes in diaphragmatic and chest wall motion in response to the addition of PEEP (28). This would explain the differences we found between the spontaneously breathing infants and the infants on respiratory support.

Similar to our study, Van der Burg et al. (29), in a group of preterm infants on CPAP or with nasal cannula, found that immediately after a position change there was a shift in ventilation distribution with the effect weaning off over the next $3 \mathrm{~h}$. This finding suggests that more regular position changes may be advantageous.

In the infants on CPAP, there was also increased regional impedance amplitude in the right lung after $2 \mathrm{~h}$. This phenomenon of increased ventilation in the right lung has previously been reported in premature infants $(9,13,14)$ and it has been suggested that it may be the result of an anatomical structure wherein the right main bronchus is straighter than the left (14) and that there is less lung tissue in the left hemi-thorax (9).
EEL in spontaneously breathing preterm infants is maintained above passive resting volume through a combination of mechanisms which include braking of the expiratory flow to prolong the time constant of the respiratory system, decreasing the expiratory time by increasing respiratory rate, and using respiratory muscle activity to dynamically elevate EEL $(30,31)$. In the infants on CPAP there was an increased EEL at $2 \mathrm{~h}$ which corresponded with improved homogeneity and increased regional ventilation of the posterior lung. This is not surprising as it is widely acknowledged that CPAP increases EEL (32-34). It has been speculated that the dynamic volumepreserving mechanisms resulting from expiratory flow braking are not required during CPAP, as the constant pressure passively elevates functional residual capacity $(30,32)$.

Despite the similarities between ventilated infants and infants on CPAP for both GI and regional ventilation; the pattern was a little different for EEL. Even though there was an increase in EEL at $2 \mathrm{~h}$ for the ventilated infants, this did not reach significance. This could be because of the large variability in EEL between the ventilated infants or as speculated by Van der Burg et al. (25) that spontaneous breathing with control of the upper airways (CPAP) may have a different effect on EEL compared with breathing through an endotracheal tube supported by positive pressure.

As found in other studies, the fact that there was no change in oxygenation suggests a change in posture results in the lack of significant alveolar recruitment/derecruitment $(25,29)$.

One of the strengths of this study is that the position change was randomly assigned and the findings were consistent for all positions. Clinicians caring for infants with respiratory distress are familiar with the concept that most infants improve their respiratory status after any position change but time is needed to see the effect.

Another component that we have not addressed in this study is the change in lung perfusion that occurs during a position change. Having used a filter that excludes most of the cardiac induced impedance change, such an effect is less likely to impact on the findings.

In this study, the first measurement was taken 30 mins after a position change which should have been adequate time for stabilization of regional distribution. Respiratory variables have been found to stabilize within 30 mins after a change in body position in preterm infants on CPAP (35).

The sleep state of the infant was not recorded during the study and it is possible that the infants were more aroused at baseline which may have resulted in the infant taking deeper breaths.

In view of the length of time infants are left between position changes in NICU's, a limitation of this study was that the infants were only investigated for $4 \mathrm{~h}$ before being repositioned whereby their lung function returned to baseline again. It may be possible that the respiratory parameters that improved over time could have demonstrated a subsequent change in function after the 4-h measure. Further research investigating longer time periods would have been able to identify this information. 
Electrode placement on small preterm infants can prove difficult when using EIT. Electrodes that are ineffectively affixed to the infant can increase recorded noise and alter the measure. The image produced by the back projection algorithm is created on the mathematical basis that the chest shape is unchanging, whereas it is in fact reliant on the population investigated. EIT is only capable of measuring relative and not absolute changes in lung volume but as the measurements taken were all in terms of relative change, this does not pose a problem.

\section{Conclusion}

Regional ventilation distribution is influenced by time with the effect of time being independent of changes in ventilation distribution due to body position. Our results show that the fact of a "change" in body position leads to a change in lung function and not just the position on its own.

Differences exist between infants on ventilatory support compared with those infants who are spontaneously breathing. Infants receiving ventilatory support have a physiological peak in lung function after $2 \mathrm{~h}$ which remains above baseline at $4 \mathrm{~h}$. A change in body position facilitates an improvement in lung function in infants on ventilatory support.

\section{METHODS}

\section{Design}

A randomized crossover study design was used to investigate the changes in lung function that occur in preterm infants over a 12-h period. Three different groups of preterm infants were studied: those who were mechanically ventilated; preterm infants on nasal CPAP; and spontaneously breathing infants without respiratory support or oxygen. Over the $12 \mathrm{~h}$ infants were randomly allocated as to the order of three different body positions (supine, quarter prone right side uppermost, and prone head turned to the left), with position changes occurring every $4 \mathrm{~h}$. In the mechanically ventilated infants and those on CPAP, suction was performed prior to each position change. Allocation was concealed with the use of sequentially numbered sealed opaque envelopes. The assessor was blinded to the position and time of measurement.

\section{Subjects}

Infants were recruited from the neonatal intensive care unit of the New Life Centre at the Mater Mother's Hospital in South Brisbane, Queensland, Australia. Inclusion criteria were infants $\leq 32 \mathrm{wk}$ gestation and body weight $>750 \mathrm{~g}$. Exclusion criteria were infants that were cardiopulmonary unstable, receiving high frequency oscillating ventilation, required or have had recent surgery, poor skin integrity, air leak syndrome, lung collapse or consolidation and infants born to mothers aged $<18 \mathrm{y}$ of age. Approval to approach parents was given by a neonatologist once the infants were deemed medically stable. Informed written consent was obtained prior to recruitment. The study conformed to the National Health and Medical Research Council National Statement on Ethical Conduct in Research Involving Humans (2007) and was approved by the Human Research Ethics Committee of the Mater Health Services and Australian Catholic University Ethics Committee.

\section{Measures}

Ventilation distribution was measured using EIT. The high reproducibility of this EIT measurement method has been reported previously (26). Measurements were performed using the Gottingen Goe-MF II electrical impedance tomograph (VIASYS Healthcare, Hochberg, Germany), delivering current injections through sixteen Ag/AgCI electrodes (Kendall, Kittycat 1,050NPSM, Tyco Healthcare group, Mansfield, MA) placed around the infants' chest at the level of the nipples. Measurements occurred at a frame rate of 44 images per second and at a frequency of $100 \mathrm{kHz}$. A 60 -s baseline measurement was obtained in the supine position prior to infants being placed in their first position. Three consecutive 60 -s measurements were then obtained at 30 -mins, $2 \mathrm{~h}$, and $4 \mathrm{~h}$ in each of the three different positions and referenced to the baseline measurement. The EIT data were band pass filtered to eliminate interference by including the first and second harmonic of the respiratory rate (36). A cut-off mask of $20 \%$ of the peak impedance signal was applied (37). As the preterm infant often displays a periodic respiratory pattern, noise-free, regular sections of data were selected for analysis (9). Data was further analyzed off-line using Matlab 7.1 (The MathWorks, Natick, MA).

Regional impedance amplitudes were calculated for the global lung and for the anterior, posterior, right and left side of the lungs to quantify changes in the tidal volume of specific regions in the lung. The end inspiratory and end-expiratory impedance differences were averaged for each of these measurements. To account for the unequal number of pixels analyzed in the different ROIs, the average amplitude for each ROI was reported.

End expiratory level (EEL) can be determined by using EIT to detect the relative impedance amplitude at end-expiration hence EEL is compared with functional residual capacity. The changes in EEL of the anterior, posterior, left, and right lungs and for the global lung in all three positions were analyzed and compared.

The GI index is used to measure tidal volume distribution throughout the global lung. In this study the GI index was used as an indicator of overall change in inhomogeneity of ventilation quantifying the total volume distribution within the lungs (23). The median value of difference in impedance between end inspiration and end expiration was calculated. The median value of each tidal image was generated and then the sum of all differences between individual pixels calculated. This sum was then normalized to the number of pixels analyzed to make the GI universal (23). A higher GI index value is equivalent to a greater ventilation inhomogeneity.

The secondary outcome measures were manually recorded at the time of each EIT recording. Oxygen saturations via a pulse oximeter sensor (Nellcor Oxisensor II N25 sensor, Tyco Healthcare Group, Pleasanton, CA), heart rate, RR and fraction of inspired oxygen were recorded using the Siemens SC 7,000/9,000XL bedside cardiorespiratory monitor loaded with custom software VF6.4-W (Drager Medical Systems, Danver, MA). From the collected data the oxygen saturation/fraction of inspired oxygen ratio was calculated (38).

As no previous studies had used EIT in preterm infants, a power calculation for sample size was based on oxygenation data. Results indicated that 21 subjects were required to retain $90 \%$ power at a $P<0.05$ level of significance with a $10 \%$ change in measure.

\section{Statistics}

Results are described using means and confidence intervals or SD for the demographic data. To determine differences in regional impedance amplitudes, EEL, GI, and physiological parameters, generalized linear models were used to investigate the main effects and interactions for the factors position and time. In each position the 30-min measure was used as the baseline. A $P$-value of $<0.05$ was considered significant. All statistical analyses were performed using SPSS version 22.0 (IBM Corporation, Somers, NY).

\section{ACKNOWLEDGMENTS}

We thank all the parents and caregivers of preterm infants who volunteered to participate in the study.

\section{STATEMENT OF FINANCIAL SUPPORT}

This work was financially supported by a Mater Foundation grant, South Brisbane, Australia.

Disclosure: There are no conflicts of interest to disclose.

\section{REFERENCES}

1. Friedrich L, Stein RT, Pitrez PM, Corso AL, Jones MH. Reduced lung function in healthy preterm infants in the first months of life. Am J Respir Crit Care Med 2006;173:442-7. 


\section{Articles $\mid$ Houghet al.}

2. Joshi S, Kotecha S. Lung growth and development. Early Hum Dev 2007;83:789-94.

3. Behrman RE, Butler AS. Preterm Birth: Causes, Consequences, and Prevention. Washington, DC: The National Academies Press, 2007:313-346

4. Perez-Woods R, Malloy MB, Tse AM. Positioning and skin care of the lowbirth-weight neonate. NAACOGS Clin Issu Perinat Womens Health Nurs 1992;3:97-113.

5. Byrne E, Garber J. Physical therapy intervention in the neonatal intensive care unit. Phys Occup Ther Pediatr 2013;33:75-110.

6. Levy J, Habib RH, Liptsen E, et al. Prone versus supine positioning in the well preterm infant: effects on work of breathing and breathing patterns. Pediatr Pulmonol 2006;41:754-8.

7. Picheansathian $\mathrm{W}$, Woragidpoonpol $\mathrm{P}$, Baosoung C. Positioning of preterm infants for optimal physiological development: a systematic review. JBI Database System Rev Implement Rep. 2009;7:224-59.

8. Dimitriou G, Greenough A, Pink L, McGhee A, Hickey A, Rafferty GF. Effect of posture on oxygenation and respiratory muscle strength in convalescent infants. Arch Dis Child Fetal Neonatal Ed 2002;86:F147-50.

9. Frerichs I, Schiffmann H, Oehler R, et al. Distribution of lung ventilation in spontaneously breathing neonates lying in different body positions. Intensive Care Med 2003;29:787-94.

10. Harrison L. Research utilization: handling preterm infants in the NICU. Neonatal Netw 1997;16:65-9.

11. Kean S. Effects on oxygen saturation levels of handling premature infants within the concepts of kinaesthetic infant handling: pilot study. Intensive Crit Care Nurs 1999;15:214-25.

12. Liaw JJ, Chen SY, Yin YT. Nurses' beliefs and values about doing cue-based care in an NICU in Taiwan. J Nurs Res 2004;12:275-86.

13. Hough JL, Johnston L, Brauer SG, Woodgate PG, Pham TM, Schibler A. Effect of body position on ventilation distribution in preterm infants on continuous positive airway pressure. Pediatr Crit Care Med 2012;13:446-51.

14. Hough JL, Johnston L, Brauer S, Woodgate P, Schibler A. Effect of body position on ventilation distribution in ventilated preterm infants. Pediatr Crit Care Med 2013;14:171-7.

15. Lupton-Smith AR, Argent AC, Rimensberger PC, Morrow BM. Challenging a paradigm: positional changes in ventilation distribution are highly variable in healthy infants and children. Pediatr Pulmonol 2014;49:764-71.

16. Heaf DP, Helms P, Gordon I, Turner HM. Postural effects on gas exchange in infants. N Engl J Med 1983;308:1505-8.

17. Davies H, Kitchman R, Gordon I, Helms P. Regional ventilation in infancy. Reversal of adult pattern. N Engl J Med 1985;313:1626-8.

18. Schibler A, Yuill M, Parsley C, Pham T, Gilshenan K, Dakin C. Regional ventilation distribution in non-sedated spontaneously breathing newborns and adults is not different. Pediatr Pulmonol 2009;44:851-8.

19. Heinrich S, Schiffmann H, Frerichs A, Klockgether-Radke A, Frerichs I. Body and head position effects on regional lung ventilation in infants: An electrical impedance tomography study. Intensive Care Med 2006;32: $1392-8$.

20. Galvin I, Drummond GB, Nirmalan M. Distribution of blood flow and ventilation in the lung: gravity is not the only factor. $\mathrm{Br} \mathrm{J}$ Anaesth 2007;98:420-8.

21. Gattinoni L, Pesenti A. The concept of "baby lung". Intensive Care Med 2005;31:776-84.
22. Hough JL, Shearman AD, Liley H, Grant CA, Schibler A. Lung recruitment and endotracheal suction in ventilated preterm infants measured with electrical impedance tomography. J Paediatr Child Health 2014;50:884-9.

23. Zhao Z, Möller K, Steinmann D, Frerichs I, Guttmann J. Evaluation of an electrical impedance tomography-based Global Inhomogeneity Index for pulmonary ventilation distribution. Intensive Care Med 2009;35:1900-6.

24. Hjalmarson O, Sandberg K. Abnormal lung function in healthy preterm infants. Am J Respir Crit Care Med 2002;165:83-7.

25. van der Burg PS, Miedema M, de Jongh FH, Frerichs I, van Kaam AH. Changes in lung volume and ventilation following transition from invasive to noninvasive respiratory support and prone positioning in preterm infants. Pediatr Res 2015;77:484-8.

26. Frerichs I, Schmitz G, Pulletz S, et al. Reproducibility of regional lung ventilation distribution determined by electrical impedance tomography during mechanical ventilation. Physiol Meas 2007;28:S261-7.

27. Walther SM, Johansson MJ, Flatebø T, Nicolaysen A, Nicolaysen G. Marked differences between prone and supine sheep in effect of PEEP on perfusion distribution in zone II lung. J Appl Physiol (1985) 2005;99:909-14.

28. Glenny RW. Determinants of regional ventilation and blood flow in the lung. Intensive Care Med 2009;35:1833-42.

29. van der Burg PS, de Jongh FH, Miedema M, Frerichs I, van Kaam AH. The effect of prolonged lateral positioning during routine care on regional lung volume changes in preterm infants. Pediatr Pulmonol 2016;51:280-5.

30. Magnenant E, Rakza T, Riou Y, et al. Dynamic behavior of respiratory system during nasal continuous positive airway pressure in spontaneously breathing premature newborn infants. Pediatr Pulmonol 2004;37:485-91.

31. Latzin P, Roth S, Thamrin C, et al. Lung volume, breathing pattern and ventilation inhomogeneity in preterm and term infants. PLoS One 2009;4:e4635.

32. Courtney SE, Pyon KH, Saslow JG, Arnold GK, Pandit PB, Habib RH. Lung recruitment and breathing pattern during variable versus continuous flow nasal continuous positive airway pressure in premature infants: an evaluation of three devices. Pediatr 2001;107:304-8.

33. Pandit PB, Courtney SE, Pyon KH, Saslow JG, Habib RH. Work of breathing during constant- and variable-flow nasal continuous positive airway pressure in preterm neonates. Pediatr 2001;108:682-5.

34. Elgellab A, Riou Y, Abbazine A, et al. Effects of nasal continuous positive airway pressure (NCPAP) on breathing pattern in spontaneously breathing premature newborn infants. Intensive Care Med 2001;27:1782-7.

35. Gouna G, Rakza T, Kuissi E, Pennaforte T, Mur S, Storme L. Positioning effects on lung function and breathing pattern in premature newborns. J Pediatr 2013;162:1133-7, 1137.e1.

36. Dunlop S, Hough J, Riedel T, Fraser JF, Dunster K, Schibler A. Electrical impedance tomography in extremely prematurely born infants and during high frequency oscillatory ventilation analyzed in the frequency domain. Physiol Meas 2006;27:1151-65.

37. Pulletz S, van Genderingen HR, Schmitz G, et al. Comparison of different methods to define regions of interest for evaluation of regional lung ventilation by EIT. Physiol Meas 2006;27:S115-27.

38. Rice TW, Wheeler AP, Bernard GR, Hayden DL, Schoenfeld DA, Ware LB; National Institutes of Health, National Heart, Lung, and Blood Institute ARDS Network. Comparison of the SpO2/FIO2 ratio and the PaO2/FIO2 ratio in patients with acute lung injury or ARDS. Chest 2007;132:410-7. 